Science, Technology and Development 35 (1): 51-53, 2016

ISSN 0254-6418 / DOI: 10.3923/std.2016.51.53

(C) 2016 Pakistan Council for Science and Technology

\title{
Tyre/Road Noise Modelling for Concrete Surface Material
}

\author{
Kai-Long Mak \\ Hong Kong Community College, West Kowloon, Hong Kong SAR, China
}

\begin{abstract}
The study describes the result of a statistical model to estimate tyre/road noise. A total number of 1635 tyre/road noise measurements were collected, using a close-proximity vehicle, from 112 trials along 3 selected road sections on concrete surface material pavements in 2012, to develop such a model in Hong Kong. Five parameters, including vehicle speed, absolute acceleration, road temperature, road surface age and road gradient were considered. Interaction effect between vehicle speed and absolute acceleration was found by principal factor analysis. The interaction effects between vehicle speed and absolute acceleration are found to be important for noise levels at frequencies below $1250 \mathrm{~Hz}$, which match the similar tyre/road noise measurement in Hong Kong.
\end{abstract}

Key words: Tyre/road noise, statistical model, close-proximity vehicle, principal factor analysis

\section{INTRODUCTION}

Sandberg and Ejsmont (2002) summarized factors that affected tyre/road noises. They include speed, road surface, tyre loading and temperature. The influence on tyre/road noise ranged from 3-25 dB. Regarding the effects of road and driving conditions on road noise, Braun et al. (2013) showed that the tyre/road noise depended on the state of driving. Accelerating conditions exhibited higher intensity levels than the constant-speed and coast-down conditions.

Jabben (2011) observed that there was a negative relationship between noise level and ambient air temperature, i.e., the measured noise level increases with decreasing ambient air temperature. This study tries to apply statistical techniques to relate tyre/road noise with all these influencing factors.

\section{MATERIALS AND METHODS}

Mak and Loh (2015) developed a statistical modelling for Hong Kong tyre/road noise in 2015. The corresponding statistical model can quantify all the possible factors and their interaction effects on tyre/road noise. A similar two stages of modeling were used in this paper with five driving factors. The development of our tyre/road noise model starts from the principal component analysis on five urban driving and road surface conditions (road gradient, surface age, road temperature, speed and absolute acceleration). The model development starting from statistical principal component analysis, it was aimed to identify the most important variables and quantify the percentage of contribution of each component. Furthermore, the result of principal components analysis can be used for indicated interaction effect between variables. The corresponding interaction effect between corresponding factors was further used for the statistical tyre/road noise model development.

Statistical stepwise regression is applied to develop our statistical model. The statistical regression model can be shown as the following form:

$$
\mathrm{SPL}_{\text {freequency }}=\sum \alpha_{\mathrm{i}} \mathrm{X}_{\mathrm{i}}+\sum \beta_{\mathrm{i}} \mathrm{X}_{\mathrm{i}} \mathrm{X}_{\mathrm{j}}
$$

where, $\alpha_{i}$ is the coefficient of parameter $X_{i}, X_{i}, X_{j}$ are the parameters have significant impacts on tyre/road noise and $\beta_{\mathrm{i}}$ is the coefficient of the interaction effect between parameters $\mathrm{X}_{\mathrm{i}}$ and $\mathrm{X}_{\mathrm{j}}$.

Data collection: The CPX method in measuring tyre/road noise as specified in the ISO/DIS 11819-2 was employed. The CPX measurement equipment was developed according the ISO standard with using two mandatory microphones; one positioned at $200 \mathrm{~mm}$ from the tyre side wall and the other at $100 \mathrm{~mm}$ above the surface. The authors (Mak et al., 2011) applied a microwave speed sensor on the CPX vehicle to measure instantaneous speed in parallel with the tyre/road noise measurement and recorded a very reliable result. The similar setting was adopted in this survey, microstar speed sensor from corrsys-datron was used for recording the continuous vehicle speed. Concrete surface is selected for study in this survey. The survey involves driving the CPX vehicle repeatedly along these selected road sections. A total of 112 segments along the 3 selected road sections were made in urban areas with a pair of SRTT, the pavement surface age, road gradient and road temperature were also recorded for analysis. 


\section{RESULTS AND DISCUSSION}

A total of 1635 tyre/road noise measurements were obtained along the 3 selected road sections. The descriptive statistics of each variable are shown in Table 1.

Model development: The principal component analysis was carried out on the data and the eigenvalues and percentage of variance represented by corresponding components are shown in Table 2. The five components are road gradient, surface age, road surface temperature, driving speed and acceleration. The results show that two components had eigen values greater than one, so these two components were selected as the principal factors. Varimax with Kaiser normalization with rotation method was applied to extract the principal components. The corresponding components are shown in Table 3.

Two components were extracted in the principal component analysis. The first component was dominated by the factor vehicle speed, which was also the only significant coefficient in the first component. This represent that $35.6 \%$ of the overall variation in the data can be represented by the factor of vehicle speed. The second component had two significant coefficients, which were vehicle speed and absolute acceleration. The second component represented $31.8 \%$ of the overall variation. While two factors were covered in same component, it represented an interaction effect between these two factors (vehicle speed and absolute acceleration). Furthermore, after the principle component analysis, $67.4 \%$ of the overall variation was represented by the two new principal components.

As an interaction factor was found to be significant, the effect of the interaction between vehicle speed and absolute acceleration on tyre/road noise was further investigated by statistical regression model. Statistical stepwise multiple regression analysis was applied to factors for the overall SPL and 5 frequency bands (500, 800, 1000, 1250 and $2000 \mathrm{~Hz}$ ) which are described in Table 4. The statistical models of each coefficient for the different types of pavement and then tyres were developed. Equation 1 can then be rewritten as follows:

$\mathrm{SPL}_{\text {freequency }}=\mathrm{C}+\sum \alpha_{1} \mathrm{v}+\sum \alpha_{2} \mathrm{Age}+\sum \alpha_{3} \mathrm{~T}+\sum \alpha_{4} \alpha+\sum \alpha_{5} \mathrm{~g}+\sum \beta_{1} \mathrm{va}$

Where:

$\alpha, \beta=$ Coefficients depending on types of road surfaces and tyres

$\mathrm{v} \quad=$ Vehicle speed in $\mathrm{m} \mathrm{sec}^{-1}$

Age $=$ Age of the road surface in months

$\mathrm{T}=$ Road temperature in ${ }^{\circ} \mathrm{C}$

$\mathrm{a}=$ Absolute acceleration in $\mathrm{m} \mathrm{sec}^{-2}$

$\mathrm{g}=$ Gradient

Table 1: Descriptive statistics for each variable

\begin{tabular}{lcccc}
\hline & Minimum & Maximum & Mean & $\begin{array}{c}\text { Standard } \\
\text { deviation }\end{array}$ \\
\hline SPL (dBA) & 92.1 & 95.4 & 93.9 & 1.0 \\
Surface age (month) & 24.0 & 38.0 & 30.6 & 7.0 \\
Gradient $(\tan \theta)$ & 0.25 & 1.15 & 0.8 & 0.5 \\
Vehicle speed $\left(\mathrm{m} \mathrm{sec}^{-1}\right.$ ) & 20.4 & 24.3 & 22.1 & 0.8 \\
Absolute vehicle & & & & \\
acceleration $\left(\mathrm{m} \mathrm{sec}^{-2}\right)$ & 0.0 & 1.0 & 0.2 & 0.6 \\
Road temperature $\left({ }^{\circ} \mathrm{C}\right)$ & 26.7 & 31.4 & 29.3 & 1.1 \\
\hline
\end{tabular}

Table 2: Eigen values and percentage of variance represented by corresponding components

\begin{tabular}{lcc}
\hline Component & Eigen values & Variance (\%) \\
\hline 1 & 1.88 & 35.6 \\
2 & 1.59 & 31.8 \\
3 & 0.89 & 17.8 \\
4 & 0.42 & 8.6 \\
5 & 0.22 & 4.4 \\
\hline
\end{tabular}

Table 3: Result of principal component analysis

\begin{tabular}{llc}
\hline & Component & \\
& 1 & 2 \\
\hline Surface age (month) & 0.26 & 0.06 \\
Road gradient & 0.08 & 0.47 \\
Road temperature & 0.58 & 0.14 \\
Vehicle speed & $0.84^{*}$ & $0.76^{*}$ \\
Absolute acceleration & 0.50 & $0.87^{*}$ \\
\hline *Coefficient is significant at the 0.05 level &
\end{tabular}

Table 4: Statistical model output coefficients

\begin{tabular}{|c|c|c|c|c|c|c|c|c|c|}
\hline & Intercept & $\begin{array}{l}\text { Vehicle } \\
\text { speed } \\
\left(\mathrm{m} \mathrm{sec}^{-1}\right)\end{array}$ & $\begin{array}{l}\text { Surface age } \\
\text { (month) }\end{array}$ & $\begin{array}{l}\text { Ambient } \\
\text { temperature } \\
\left({ }^{\circ} \mathrm{C}\right)\end{array}$ & $\begin{array}{l}\text { Road } \\
\text { temperature } \\
\left({ }^{\circ} \mathrm{C}\right)\end{array}$ & $\begin{array}{l}\text { Absolute } \\
\text { acceleration } \\
\left(\mathrm{m} \mathrm{sec}^{-2}\right)\end{array}$ & $\begin{array}{l}\text { Interaction effect } \\
\text { (speed X absolute } \\
\text { acceleration) }\end{array}$ & Gradient & R-square \\
\hline Overall & 90.42 & 0.18 & & -0.34 & & 1.75 & 0.03 & & 0.234 \\
\hline $500 \mathrm{~Hz}$ & 105.36 & 0.31 & & -0.51 & & 1.34 & 0.06 & & 0.589 \\
\hline $800 \mathrm{~Hz}$ & 80.54 & 0.57 & & & & 1.81 & 0.04 & & 0.339 \\
\hline $1000 \mathrm{~Hz}$ & 75.48 & 0.74 & 0.01 & -0.91 & & & 0.09 & & 0.424 \\
\hline $1250 \mathrm{~Hz}$ & 90.75 & 0.65 & 0.02 & -1.01 & & 1.02 & & 3.39 & 0.232 \\
\hline $2000 \mathrm{~Hz}$ & 88.34 & 1.05 & 0.05 & -1.33 & & & & 1.96 & 0.388 \\
\hline
\end{tabular}




\section{CONCLUSION}

The interaction effect was proved to be significant in previous research by author on polymer modified friction course. Similar methodology was applied on concert surface in urban driving conditions. A same interaction effect between vehicle speed and absolute acceleration was obtained in concert surface as well. As tyre/road noise generation is too complicated to express in terms of single factor statistical model, seems considering in term of two or more factors interact effects is the solution in statistical tyre/road noise modelling. With introducing such a simple multivariate statistical analysis on principle analysis, the interaction factor was easily being single out. This will be very effective on improving urban statistical tyre/road noise modelling.

\section{REFERENCES}

Braun, M.E., S.J. Walsh, J.L. Horner and R. Chuter, 2013. Noise source characteristics in the ISO 362 vehicle pass-by noise test: Literature review. Appl. Acoust., 74: 1241-1265.

Jabben, J., 2011. Temperature effects on road traffic noise measurements. Inter-Noise 2011. Osaka, Japan.

Mak, K.L. and W.K. Loh, 2015. Statistical tyre/road noise modeling in Hong Kong on polymer modified friction course. Sci. Technol. Dev., 34: 101-104.

Mak, K.L., S.H. Lee, K.Y. Ho and W.T. Hung, 2011. Developing instantaneous tyre/road noise profiles: A note. Transp. Res. Part D: Transp. Environ., 16: $257-259$.

Sandberg, U. and J. Ejsmont, 2002. Tyre/Road Noise Reference Book. Informex, Sweden. 